\title{
History of Cardiac Anaesthesia
}

\section{The contribution of Canadian anaesthetists to the evolution of cardiac surgery}

J. Earl Wynands MD
Purpose: There have been great improvements in the management of patients with heart disease over the past 50 yr much of which has been due to the development of surgical procedures for the correction of acquired and congenital cardiac abnormalities. A great deal has been written about the surgeons and the innovative procedures they developed. They were undoubtedly courageous, imaginative, knowledgeable and skilful. Little is written about the anaesthetists who often worked in the laboratory with the surgeons and provided anaesthesia for patients having this surgery which, in the early days, was experimental. The purpose of this article is to present the contributions made by Canadian anaesthetists to the evolution of cardiac surgery.

Principal findings: The contributions have been important over five clearly discernable eras and have been identified through publications. Canadian anaesthetists wrote about their experience giving anaesthesia for mitral commissurotomy, relief of pulmonic stenosis, ligation of patent ductus arteriosus, resection of aortic coarctation, correction of simple congenital heart defects under hypothermia and myocardial revascularization. When open heart surgery was introduced,

\section{Key words}

ANAESTHESIA: cardiac, history;

HISTORY:

SURGERY: cardiac.

From the Department of Anaesthesia, University of Ottawa and Department of Anaesthesia, Ottawa Civic Hospital and Heart Institute.

Address correspondence to: Dr. J. Earl Wynands, Department of Anaesthesia, University of Otawa Heart Institute, 1053 Carling Avenue, \#H213, Ottawa, Ontario KIY 4E9.

Based on the 1995 Royal College Lecture at the CAS Annual Meeting.

Accepted for publication 23rd December, 1995.
Canadian anaesthetists working both in the United States and Canada were amongst the first to publish on surgery supported by cardiopulmonary bypass and anaesthesia for these procedures.

Conclusion: An analysis of the literature and personal, verbal and written communications with anaesthetists who experienced the trials and tribulations of anaesthesia for these early surgical procedures clearly indicates that Canadians were at the forefront in advancing anaesthesia for cardiac surgery.

Objectif: La gestion des patients souffrant de maladies cardiaques s'est grandement améliorée pendant les 50 dernières années au cours desquelles on a assisté à l'évolution des interventions chirurgicales permettant de corriger les anomalies acquises et congénitales. On a écrit beaucoup sur les chirurgiens et les interventions innovatrices qu'ils ont développées. Ils ont été sans aucun doute courageux, imaginatifs, compétents et habiles. Peu a été écrit sur les anethésistes qui souvent travaillaient en laboratoire avec les chirurgiens et administraient l'anesthésie d̀ des patients soumis à une chirurgie qui était pour le moins expérimentale. L'objectif de cet article est d'exposer la contribution des anesthésistes canadiens à l'évolution de la chirurgie cardiaque.

Principales constatations: Cette contribution s'est étalée sur cinq périodes distinctes. Les anesthésistes canadiens ont décrit leur expérience de l'anesthésie pour la commissurotomie mitrale, la correction de la sténose pulmonaire, la ligature du canal artériel, la correction de simples anomalies cardiaques congénitales sous hypothermie et la revascularisation du myocarde. Au moment de l'introduction de la chirurgie à coeur ouvert, les anesthésistes canadiens qui exerçaient aux Etats-Unis et au Canada ont été les premiers à publier sur la chirurgie assistée par la circulation extracorporelle et sur l'anesthésie adaptée à celte chirurgie.

Conclusion: L'analyse de la littérature, complétée par des communications personnelles verbales et écrites avec des anesthésistes qui ont connu les essais et les tribulations de 
l'anesthésie pour ces interventions montre clairement que les canadiens étaient à l'avant-garde des progrès de l'anesthésie pour la chirurgie cardiaque.

The improved quality of life and life expectancy in patients with cardiac disease is a testimony to the success of pioneers in cardiac surgery and anaesthesia. Much has been written about the development of cardiac surgery but there has been little emphasis on the role played by anaesthesia. This article will focus on some of the important contributions made by anaesthesia to the evolution of cardiac surgery and emphasize contributions made by Canadians. Information has been gleaned from published literature and a great deal from letters and conversations with anaesthetists in Canada who experienced the early days. of cardiac anaesthesia.

The Ether Day painting by Hinckley commemorates the first demonstration of ether anaesthesia in the Etherdome of the Massachusetts General Hospital on October 16th, 1846 (Figure 1). When the surgery was completed Professor Warren turned to the gallery and, with tears in his eyes, said "Gentleman this is no humbug." On that day the infant specialty of Anaesthesia was born. The first ether anaesthetic had actually been given on March 30th, 1842 by Dr. Crawford Long, a General Practitioner from Jefferson Jackson County, Georgia but for an unexplained reason he did not report it until after Morton had given his demonstration.

In my estimation, anaesthesia was ready to take on cardiac surgery about 1942 . By that time, oxygen and ether had been shown to be a reliable safe anaesthetic, the blood pressure cuff and stethoscope had been used for about forty years to monitor patients during anaesthesia and the Cambridge Simplitrol portable ECG machine, although cumbersome, was being recommended for perioperative use. The latter had been introduced by Dr. Wing. Smith, a general practitioner from Providence, Rhode Island. The endotracheal tube was in general use, blood banks had been established and Dr. Harold Griffith in Montreal had introduced d-tubocurarine into the practise of anaesthesia which made controlled ventilation in light anaesthesia possible.

\section{First era}

The first era occurred well before anaesthesia was ready to take it on. In 1902 Sir Lauder Brunton had published in the Lancet that he believed surgery might relieve the signs and symptoms of mitral stenosis. Billroth, the gastrointestinal surgeon, had written before the turn of the century that surgeons who would operate on the heart should lose their respectability, a view which apparently

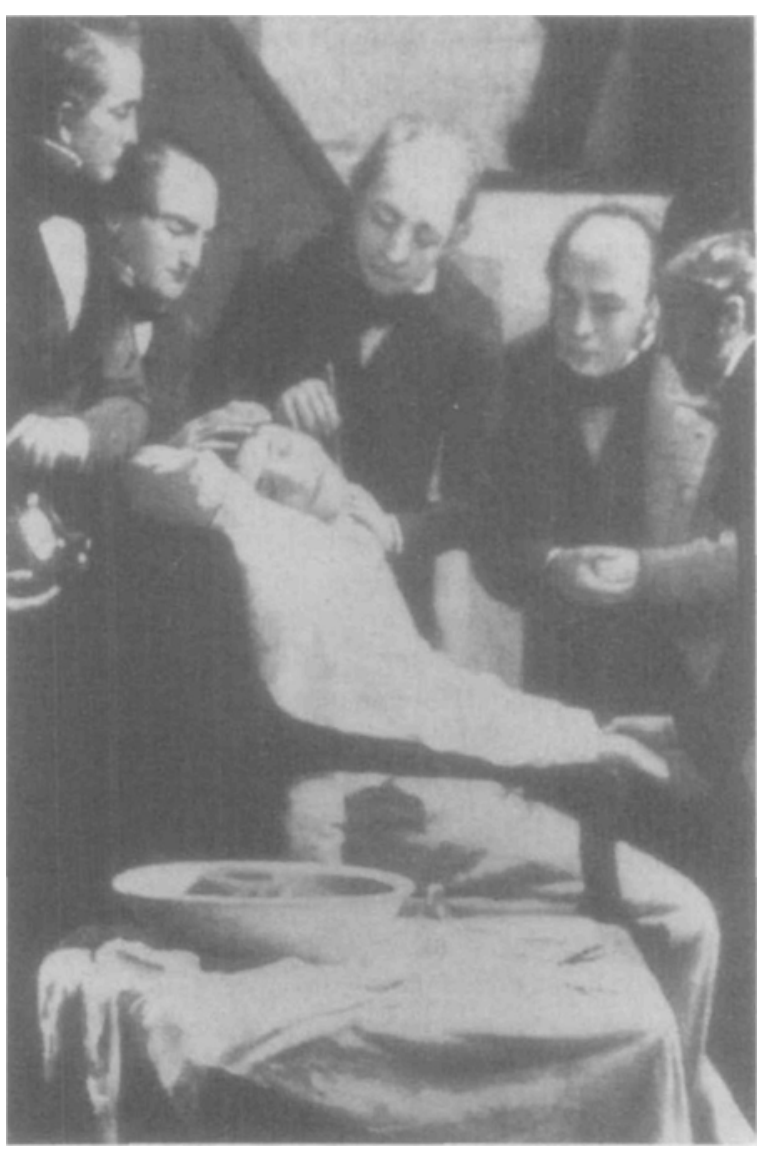

FIGURE 1 The Ether Day painting by Robert C. Hinckley: The patient, Edward Gilbert Abbott, has a tumor on his neck and reclines on a chair in the center of the painting. W.T.G. Morton, a dentist who would give the anaesthetic, holds the glass ether vaporizer, and the surgeon Professor John Warren, stands above the patient. (Reprinted, with permission, of Dr. L. Vandam and the publisher: Charles Frederick Heywood. House Surgeon at the Ether Demonstration. Anesthesiology 1995; 82: 772-8.)

was widely held. In spite of this, surgeons attacked the mitral valve. In 1922, Allan and Graham of Philadelphia, attempted to split the mitral valve. They believed that visual control was necessary and for this purpose designed a primitive endoscope. While trying to introduce it into the heart the atrium tore and the patient died. On May 20th, 1923, Cutler and Levine of Boston carried out the first successful surgery for mitral stenosis. The patient was a 12 year old girl and the occasion was the tenth anniversary of the Peter Bent Brigham Hospital in Boston. She was anaesthetized with oxygen and ether via nasal cannula. The surgeons used a valvulotome, similar to a tonsillotome, that was plunged into the apex of the left ventricle, advanced towards the mitral valve, which they had done many times in ani- 
mals and, on feeling the resistance of the valve quickly made medial and lateral cuts. The valvulotome was withdrawn and a pursestring tied. The patient was shown to the doctors attending a symposium on the second postoperative day. She survived four years before dying of a cerebral embolus.

Cutler and Levine operated on three other patients but all died. Dr. Harold Segall, author of "Pioneers of Cardiology in Canada 1820-1970"' was a cardiology fellow in 1923 at Harvard. After the first operation, he was contacted by Cutler to seek out a second patient. At the time, he was caring for a young Irish immigrant woman, 21 years of age, who was working as a maid and finding it difficult to climb stairs. She had no relatives and few friends and relied on Dr. Segall's advice. He advised her to have surgery during which she died. Dr. Segall wrote of his anguish for referring this young woman for surgery. He would feel partially vindicated when a patient that he referred to the cardiac surgeon, Eduard Gagnon, at Nôtre Dame Hospital in Montréal in 1950, was the first to have a successful mitral commissurotomy in Montréal.

In 1925, Suttar of London, using a left atrial approach, introduced his finger through the atrial appendage and characterized the fire hose jet of mitral insufficiency. The 14 year old female patient had been thought to have mitral stenosis but to his disappointment Suttar found she had mitral insufficiency. He did, however, put his finger through the valve. Nothing could be done to correct the regurgitation but, in spite of this, the patient lived for seven years during some of which time she had improved exercise tolerance. Suttar had demonstrated that the mitral valve could be safely approached through the left atrium. The anaesthetic was air, alcohol, chloroform and ether insufflated through a catheter placed in the trachea and the patient breathed spontaneously. It was administered by Dr. John Challis who was a young surgeon working with Suttar. ${ }^{2}$

That ended the first era of cardiac surgery. Mitral commissurotomy would lay in abeyance for 25 years because physicians believed the main problem lay in the rheumatic process of the myocardium. In 1945, Bailey of Philadelphia revived the surgical attack on the mitral valve. He used a back biting instrument which he introduced into the left atrium through the left atrial appendage with the intention of taking bites out of the stenosed valve. The first patient died when the atrium tore. He tried again in 1946 but this time he was unable to pass the instrument through the stenotic valve. The patient began to deteriorate quickly and, recalling the Suttar operation of 1925, he introduced his finger into the left atrium, felt the valve and split it. The patient lived for four days before dying of pulmonary oedema due to excessive fluid therapy. In 1948, Bailey performed his first successful mitral commissurotomy. It had been accomplished about the same time by Harkin of Boston and Brock of London and, soon, thoracic surgeons all over the world would be carrying out mitral commissurotomies.

\section{Second era}

The second era of cardiac surgery began with Beck and Shaughnessy who, in 1935, attempted to revascularize the myocardium by inserting talcum powder into the pericardial sack and wrapping the heart in omentum. Gross successfully ligated a patent ductus arteriosus in 1939 and Blalock corrected coarctation. In 1945 the Blalock Taussig shunt was introduced for the correction of congenital cyanotic heart disease. In 1948, in addition to Bailey's mitral commissurotomy, Hufnagel introduced his valve for the treatment of aortic insufficiency and, in 1950, Bailey carried out a closed aortic commissurotomy for the treatment of aortic stenosis.

The first publication on anaesthesia for cardiac surgery was by Harmel and Lamont, published in Anesthesiology in $1946 .^{3}$ They gave anaesthetics for Blalock and the paper was entitled "Surgical Correction of Congenital Pulmonic Stenosis." They reported 100 cases with a mortality rate of $23 \%$. The patients were premedicated with morphine or nembutal and atropine or scopolamine. Heavy sedation was produced to avoid struggling and aggravation of cyanosis. Induction of anaesthesia was with cyclopropane or vinesthene and maintenance was with cyclopropane and/or ether. Ventilation was spontaneous or gently assisted during inspiration when the chest was open to avoid mediastinal flap. In some patients the trachea was not intubated. Harmel and Lamont used a to-and-fro canister for $\mathrm{CO}_{2}$ absorption and none of the patients had chest drains inserted at the end of surgery. Causes of mortality included misdiagnosis, postoperative bleeding, pneumothorax and thrombi in the shunts. Dr. Kenneth Keown (Figure 2) published the first monograph on anaesthesia for cardiac surgery in $1956.4 \mathrm{He}$ had given the anaesthetic for Bailey's first successful mitral commissurotomy in 1948, just two years after he finished his anaesthesia training at Hahneman Hospital, Philadelphia. In the monograph he made the point that cardiac surgery was made possible by the development of several independent factors: anaesthesia for patients having a thoracotomy; the development of antibiotics; the organization of blood banks; and the development of cardiac surgical techniques by surgeons with courage, skill, imagination and vision. Each surgical procedure was an experiment and each experiment suggested another experiment. These operations could only 


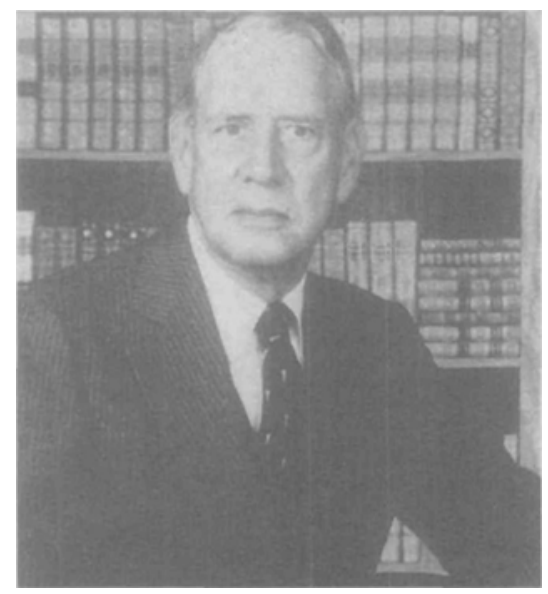

FIGURE 2 Dr. Kenneth Keown: Published the first monograph on cardiac anaesthesia.

have been possible when the patients were anaesthetized by physicians competent to deal with the serious physiological disturbances caused by surgery and possibly aggravated by anaesthesia. One can imagine the difficulty in giving an anaesthetic in 1948 for the implantation of a Hufnagel valve in the descending aorta of a patient with aortic insufficiency when the surgeon cross clamped the aorta. Cardio-active and vasoactive drugs, and monitoring techniques upon which we now rely for cardiac anaesthesia were not available. Today's cardiac anaesthetist would be hard pressed to work in that environment. Another independent factor was the referral of patients by cardiologists who believed in cardiac surgery and the final factor was the courage of the patients who agreed to have this experimental surgery. ${ }^{4}$

Dr. Keown, in his monograph, acknowledged that Canadian surgeons and anaesthetists were making a valuable contribution to the second, era of cardiac surgery. Dr. Stephen Evelyn and Dr. Iain MacKay gave anaesthetics for Dr. Gordon Murray in Toronto. They presented a paper at an International Anesthesia Research Society meeting held in Quebec City in 1953 that was published the following year in Current Researches in Anesthesia and Analgesia. ${ }^{5}$ This was the first paper on anaesthesia for cardiac surgery published by Canadian anaesthetists. In the paper, they related their experience on over 800 cases which they had anaesthetized between 1946 and 1953. They described their technique for mitral commissurotomy, ligation of a patent ductus arteriosus, coarctation and pericardectomy. They recommended thiopentone, nitrous oxide, oxygen and ether with decamethonium or d-tubocurarine used for muscle relaxation. It was a remarkable contribution, for its time, as they described an anaesthetic technique that dated back almost to the beginning of the second era of cardiac surgery.

The Canadian Anaesthetists' Society Journal was first published in 1954 and Dr. R.A. Gordon was the Editor-in-Chief. Dr. G. Fortin and Dr. R. Létienne, who were anaesthetists at Nôtre Dame Hospital in Montréal, described the prophylaxis and treatment of cardiac arrest in the first issue of the journal. ${ }^{6}$ It was Dr. Guy Fortin, in the winter of 1957, who supervised the author for his first anaesthetic for a cardiac surgical procedure, a Vineberg operation, when a resident in the McGill diploma course at the Veteran's Hospital in Montreal The first paper on anaesthesia for cardiac surgery appearing in the Canadian Anaesthetists' Society Journal was in 1955. It was on the use of nitrous oxide and succinycholine during mitral commissurotomy by Dr. David Little and Dr. George Sutton, anesthesiologists at the United States Naval Hospital in Great Lake, Illinois. ${ }^{7}$ The anaesthetic technique they recommended may surprise some but not anaesthetists of the time. Premedication was with nembutal and demerol, induction. of anaesthesia was with small amounts of thiopentone and anaesthesia was maintained with nitrous oxide, oxygen and a succinylcholine infusion. They chose succinylcholine because they believed it to be non-toxic. The patients were maintained just short of complete muscle paralysis as evidenced by respiratory effort: there were no twitch monitors. Increments of demerol were given for analgesia and the tracheas were extubated in apnea, i.e. the administration of succinylcholine was increased at the end of the operation until the patients were no longer making a respiratory effort. The endotracheal tube was then removed and the lungs were ventilated with oxygen via a face mask until the patients were breathing spontaneously and awake in the operating room.

\section{Third era}

Dr. William Bigelow, a surgeon at the University of Toronto and on the staff of the Toronto General Hospital, published his experimental work with oxygen transport and utilization in dogs at low body temperatures in the American Journal of Physiology in $1950 .{ }^{8}$ He proposed that hypothermia be used to permit open heart surgery. It was extremely controversial for, at that time, it was thought important that patients should be maintained normothermic.

Dr. John Lewis of St. Louis, Missouri, was the first surgeon to use hypothermia for the correction of an ASD which is the beginning of the third era of cardiac surgery. Between 1952 and 1955 he operated on 33 patients using hypothermia with a $12 \%$ mortality rate. 


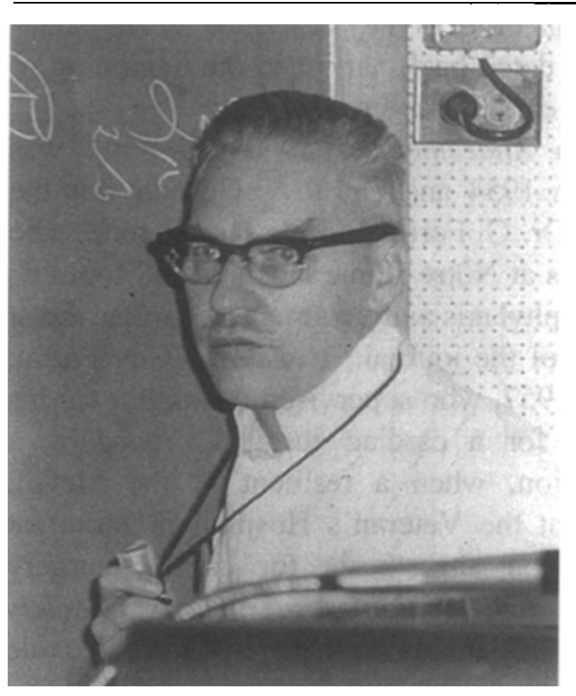

FIGURE 3 Dr. A. Code Smith: Director of Cardiac Anaesthesia at the Children's Hospital in Toronto from 1952-56. He published the second paper on anaesthesia for cardiac surgery and the first by a Canadian to appear in the Canadian Anaesthetists' Society Journal.

Hypothermia was first used in Toronto in 1954. Dr. Code Smith (Figure 3) was the Director of Cardiac Anaesthesia at the Children's Hospital between 1952 and 1956. He published the second paper on anaesthesia for cardiac surgery and the first by a Canadian to appear in our journal. It was on anaesthesia for the correction of congenital heart disease and published in October, $1955 .^{9} \mathrm{He}$ recommended the lytic cocktail, that is, chlorpromazine, promethazine and demerol supplemented with thiopentone, nitrous oxide and d-tubocurarine for patients having cardiac surgery under hypothermia. As I reviewed the paper I was surprised that he devoted a short paragraph to patients having cardiac surgery supported by cardiopulmonary bypass (CPB). The first use of CPB in Canada is attributed to the surgeon Dr. John Callaghan of Edmonton in 1956 but here Code Smith wrote about it in 1955. The reason for the apparent discrepancy will soon become evident.

The third paper and the second by a Canadian on anaesthesia for cardiac surgery to appear in the Canadian Journal of Anaesthesia was by Dr. Barrie Fairley, Director of Cardiac Anaesthesia at the Toronto General Hospital. He described hypothermia for adult cardiovascular surgery in $1957 .{ }^{10} \mathrm{He}$ concentrated on the metabolic disturbances that might be encountered in patients having hypothermia for cardiac surgery. The anaesthetic technique used by Code Smith and Barrie Fairley had been developed by Dr. Stuart Vandewater who gave anaesthetics for neurosurgery at the Toronto General Hospital and who had employed hypothermia

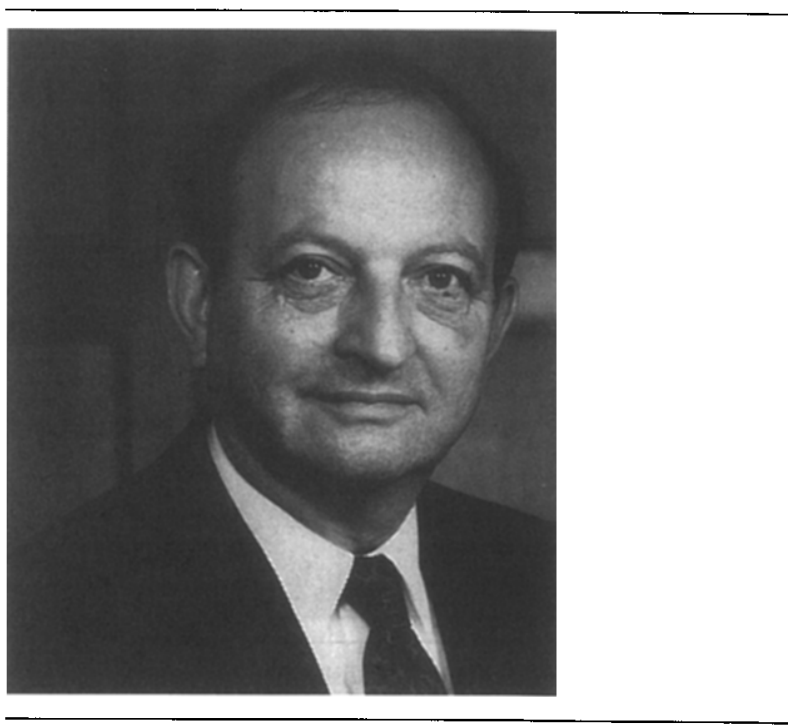

FIGURE 4 Dr. Stuart Vandewater: developed a technique of anaesthesia for patients who would benefit from hypothermia while undergoing neurosurgery at the Toronto General Hospital.

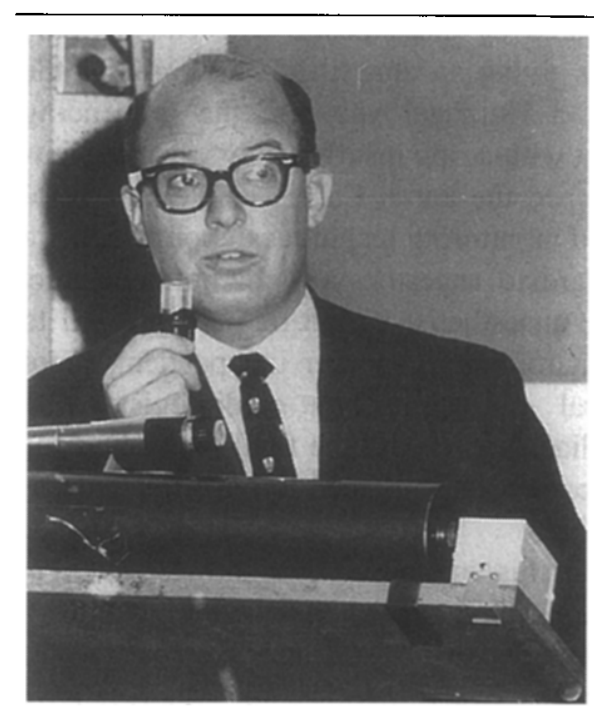

FIGURE 5 Dr. Alan Conn: Director of Cardiac Anaesthesia at the Children's Hospital in Toronto in 1957.

for some neurosurgical procedures. Dr. Vandewater (Figure 4) was the President of the Canadian Anaesthetists' Society in 1967 and served as Honorary Secretary for many years.

Dr. Alan Conn (Figure 5) took over from Code Smith as the Director of Anaesthesia for Cardiac Surgery at the Children's Hospital in Toronto in 1957. He would become the Chief of Anaesthesia at the Sick Children's Hospital and organized the first pediatric intensive care 
unit run by anaesthetists in Canada in 1971. Dr. Conn, who was the recipient of the Gold Medal of the Canädian Anäesthetists' Society in;1994, wrote to me to say that he was "appalled by the dearth of information aivailable for the early cardiac surgery procedures."

In 1954 a core temperature of $32.3^{\circ} \mathrm{C}$ was used during Blalock procedures and correction of coarctation to prevent neurological injury and deeper hypothermia, to a temperature of $29-30^{\circ} \mathrm{C}$, was used for ASDs and the correction of congenital pulmonary stenosis where the occlusion time would be less than six minutes. He told me that by 1.961 they had performed 157 cases, 100 for ASDs and 57 for pulmonary stenosis with success in 105 cases. Conn published his experience with 63 consecutive ASD secundums operated on under hypothermia. For the early cases of the series anaesthesia was provided with nitrous oxide, oxygen and ether or cyclopropane whilst the majority received halothane and it is remarkable that there was no death in the 63 cases. In the article the pathophysiology of ASD, anaesthetic management, hypothermia and complications : were described in detail. Important complications included ventricular fibrillation, severe blood loss, air "emboli with' delayed awakening and mis-diagnosis. " On removal of the occlusion clamp the patients would develop severe systolic hypertension to about 220-240 mmHg. Dr. Conn, in collaboration with Dr. Ronald Millar, anaesthetist at the Montréal Neurological Institute who had carried out research on catecholamines, described, in 1960, the high endogenous catecholamine concentrations on release of the occlusion clamp as the cause of the hypertension. ${ }^{12}$ Patients were cooled using cooling blankets - or by placing bags of ice in the groins, the axillas and around the head and neck and sometimes the children were packed in ice.

Dr. William Mustard, a surgeon, began to carry ,out research on CPB at the Toronto General Hospital in 1952. The first pump, built by Dr. Campbell Cowan at the Banting Institute, University of Toronto, consisted of pressure bulbs of a sphygmomanometer which were squeezed rhythmically by metal plates. Two pairs of monkey lungs suspended in flasks (Figure 6), were used to oxygenate the blood. One stem of a Y-shaped glass tube was inserted into the trachea, one end connected to an oxygen source, and the lungs were inflated by occluding the open limb of the glass tube with a thumb. The lungs would deflate when the thumb was removed. Dr. Conn told me that he could "vouch for the fatigue that would develop in the thumbs with time as the lungs became progressively more oedematous and difficult to inflate." Between 1952 and 1955 the pump was used on 21 cases with limited success: there were only three survivors. ${ }^{13}$ Dr. Mustard was the first surgeon to use CPB

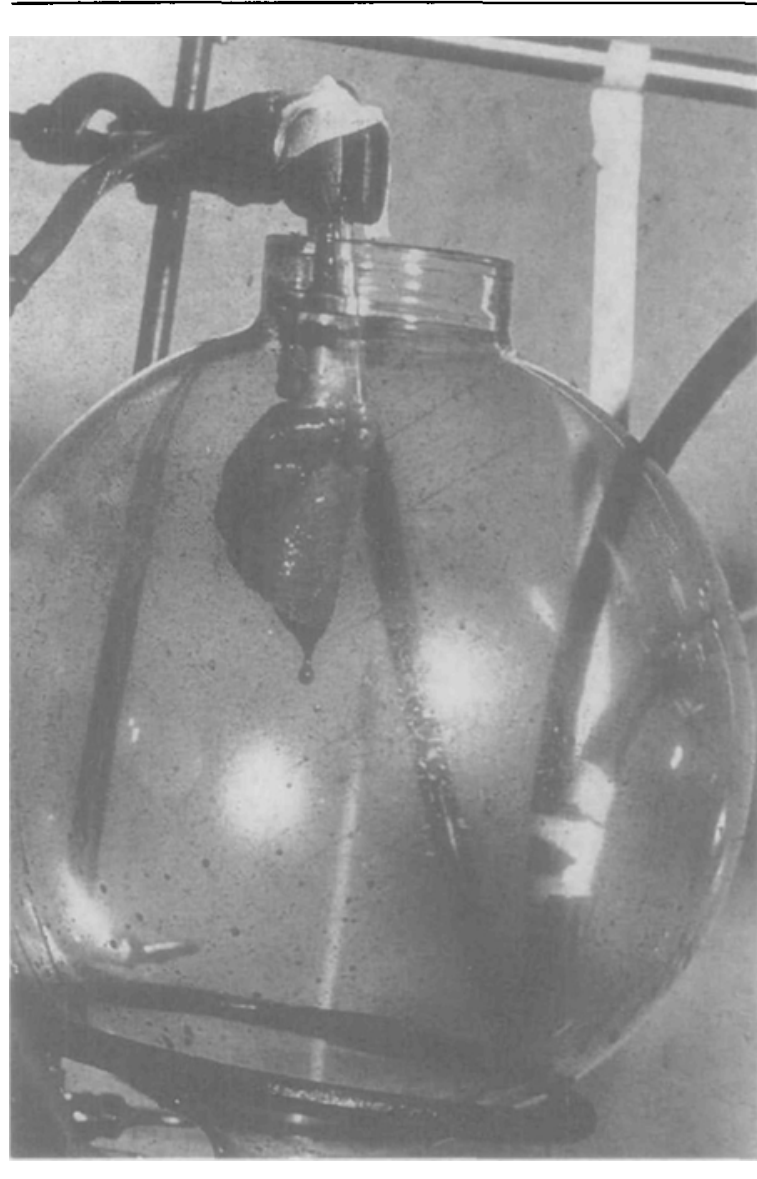

FIGURE 6 Monkey lungs suspended in a flask were used as a biological oxygenator in a cardiopulmonary bypass machine designed by Dr. Campbell Cowan at the Banting Institute, Toronto.

clinically with a biological lung and this explains the earlier comment concerning Code Smith's article.

\section{Fourth era}

Dr. Arthur Vineberg (Figure 7) of Montréal, on demobilisation from the Armed Forces in 1945, carried out research on myocardial revascularization at the Donner building, McGill University. He believed that the implantation of the left internal mammary artery in a tunnel of the left ventricle would lead to myocardial revascularization. The first clinical procedure was carried out at the Royal Victoria Hospital in Montreal in 1950 and consisted of dissecting the left internal mammary artery free from the sternum and pulling it into a tunnel which had been created in the left ventricle that did not communicate with its lumen. The free end of the internal mammary artery and two or three intercostals were allowed to bleed into the tunnel. The blood would drain off in venous sinusoids. Eventually, an anastomo- 


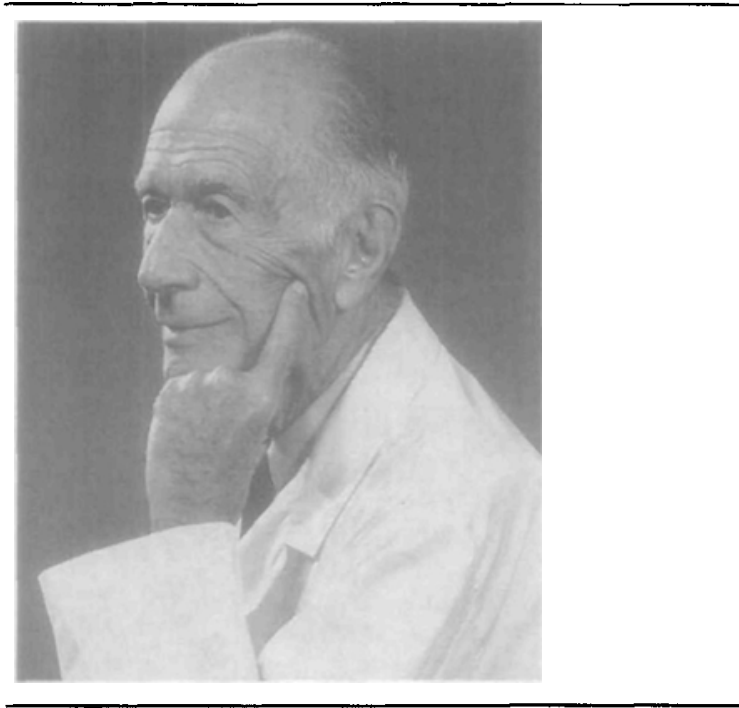

FIGURE 7 Dr. Arthur Vineberg: pioneered myocardial revascularization by implanting the left internal mammary artery into a tunnel of the left ventricular myocardium.

sis would be created with the coronary microcirculation. (Figure 8)

Dr. Arthur Sheridan (Figure 9), when he joined the anaesthesia staff at the Royal Victoria Hospital in Montréal in 1957, readily took on the challenge of anaesthetizing these high risk patients. When the author joined the department as a Clinical Fellow in 1958 he worked with Dr. Sheridan. At that time patients were premedicated with nembutal, morphine and atropine and were brought down to an induction room where they were anaesthetized with small increments of thiopentone and allowed to "breathe down" with nitrous oxide, oxygen and ether by a face mask until they were judged to be in plane 1 of the third stage of anaesthesia. They were then given $100 \mathrm{mg}$ succinylcholine $i v$, their cords sprayed with $4 \%$ xylocaine and the trachea intubated. Maintenance of anaesthesia was with nitrous oxide 5 $\mathrm{L} \cdot \mathrm{min}^{-1}$, oxygen $2 \mathrm{~L} \cdot \mathrm{min}^{-1}$, and increments of demerol (10-20 mg) iv as required. D-Tubocurarine was used for relaxation and given in 9-12 mg increments iv until the patients were no longer making respiratory effort. Ventilation was controlled manually and fluids were restricted. Dr. Vineberg insisted that the blood pressure be maintained at ward control levels with a phenylephrine drip. Monitoring was limited to taking the blood pressure with a sphygmomanometer, counting and feeling the pulse, and observing the colour of the patient. Soon, however, halothane would be substituted for ether, lead 2 of the ECG and invasive blood pressure monitored on a Sanborn polygraph. The frequent requirement for intravenous phenylephrine to maintain blood pressure led to aggressive fluid therapy with

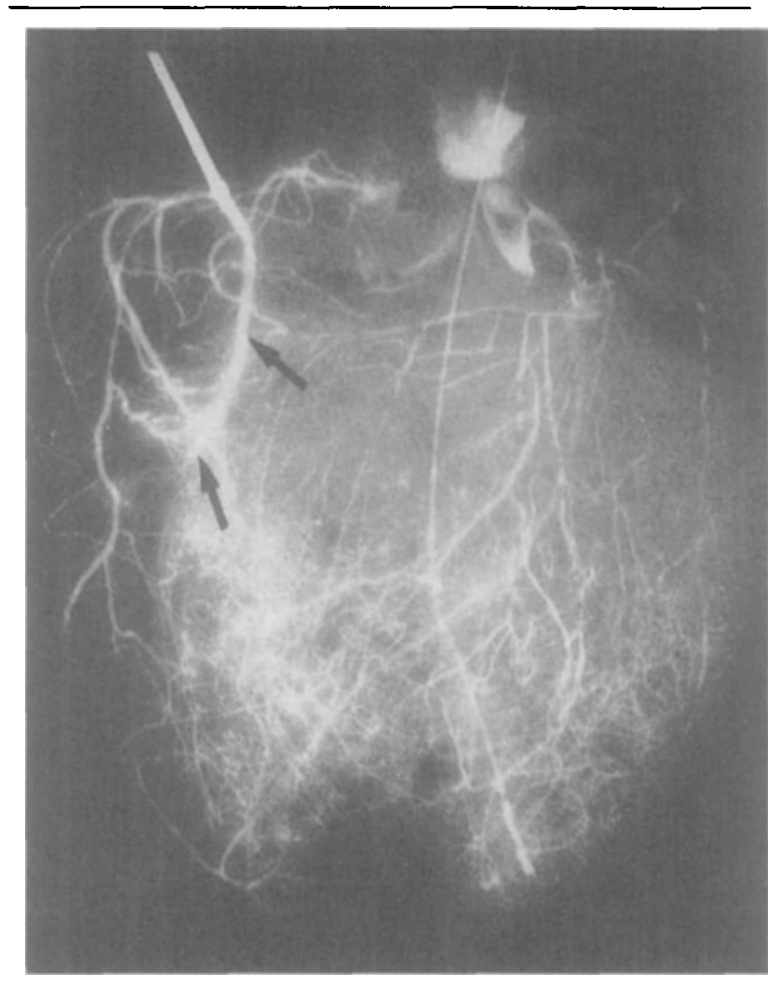

FIGURE 8 Postmortem specimen shows the internal mammary artery implanted into the left ventricular myocardium (arrows) and the anastomoses that had developed with the coronary microcirculation 10 years after surgery.

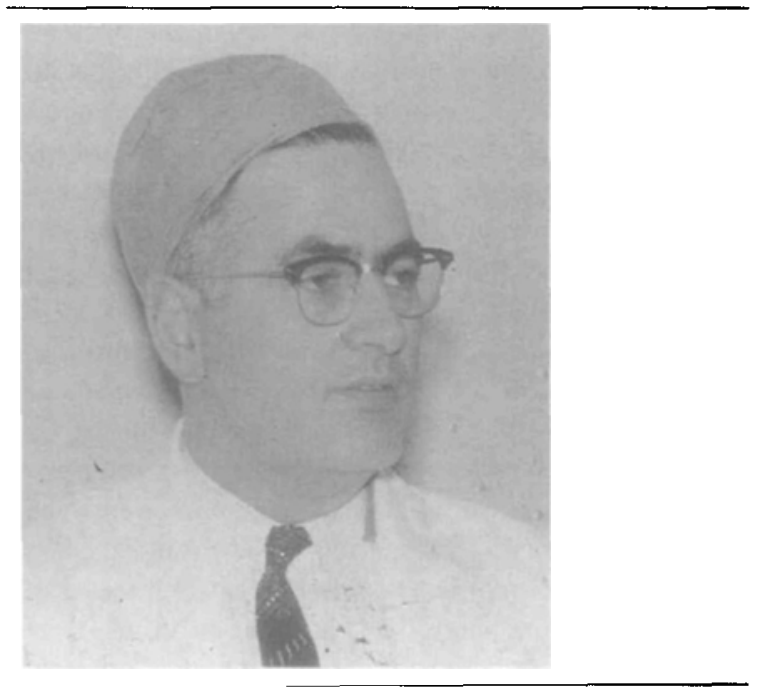

FIGURE 9 Dr. Arthur Sheridan: at the Royal Victoria Hospital in Montréal in 1957 anaesthetized high risk patients for the Vineberg Procedure.

saline and careful attention was paid to urine output, serum electrolytes, whole blood clotting time and, in about 1959 , monitoring the central venous pressure. The 
latter was measured by placing a plastic cannula in the external jugular vein and connecting it to a water manometer. Initially the trachea was extubated in the operating room but, because haemodynamic instability sometimes developed between the operating room and the recovery room, the practise of extubation in the recovery room on the morning after surgery was introduced when they were haemodynamically stable, awake, had good muscle power and maintained normal blood gases while breathing spontaneously using a $\mathrm{T}$ piece.

Dr. Sheridan was a master at maintaining patients lightly anaesthetized which was believed to be essential to avoid morbidity and mortality. He would ask the patients to open their eyes or squeeze his hand and, if they responded, he would give them increments of demerol $i v$. Awareness and recall were always a concern and so patients were never completely paralyzed. The surgery would take six to seven hours and, of course, the circulation was not supported by CPB. Nothing was written about these procedures between 1950 and 1958 .

In 1967, we published our experience relating from 1958 to that time on 120 consecutive patients. ${ }^{14}$ It was the first article on anaesthesia for myocardial revascularization. By then, an epicardectomy and free omental graft had been added to the internal mammary artery implant. The omentum had been obtained through an incision in the diaphragm via a left thoracotomy. Dr. Vineberg believed that the omentum would act as a bridge for collaterals between the heart and other structures in the mediastinum.

Patients were classified as angina Grade I or Grade II with the latter being angina at rest. A surgical death was considered to have occurred if the patients died within 28 days of surgery. There were 16 deaths in the 120 patients, five in the operating room, five in the recovery room within 72 hours and six from $72 \mathrm{hr}$ to 28 days for an overall rate of $13.3 \%$. Mortality was $32 \%$ in the angina Grade II patients and $5.8 \%$ in the angina Grade 1 patients. When the manuscript was shown to Dr. Vineberg he was very unhappy with the $32 \%$ mortality rate in the angina Grade II patients as he, in corridor conversations, would speak of a $2-5 \%$ mortality rate but he was eventually convinced that the manuscript should be published. In the article, each death was analyzed and the factors thought to be important in anaesthetizing patients for myocardial revascularization were detailed. The article attracted the attention of Dr. Leroy Vandam, editor of Anesthesiology. A symposium was published in the August issue of the journal and Dr. Arthur Keats of the Texas Heart Institute was scheduled to edit another on Cardiology and Anesthesiology in 1970 to which we contributed a chapter on anaesthesia and coronary artery disease. The results to 1970 were published and by that time 377 consecutive cases from 1958 had been performed. ${ }^{15}$ The mortality rate in Grade II patients had been reduced from $32 \%$ in 1967 to $18.9 \%$ in 1970 and the overall mortality decreased to $9.7 \%$ from $13.3 \%$. The mortality rate in the last 78 patients of the series had been reduced to only $1.3 \%$ in spite of the fact that the surgery had become much more extensive. Dr. Vincberg often implanted the left and right internal mammary arteries into the left and right ventricular myocardium via a left thoracotomy, and continued to wrap the heart in a free omental graft. The surgery often took 12 or more hours. Factors regulating myocardial oxygen delivery and consumption were reviewed in detail. Preoperative preparation, preoperative medication, anaesthetic technique and monitoring, postoperative care, complications and their management were dealt with at length. The article attracted considerable attention and the Royal Victoria Hospital at McGill University became a centre of expertise for the anaesthesia management of patients with coronary artery disease.

\section{Fifth era}

We now come to the fifth era of cardiac surgery, that supported by $\mathrm{CPB}$. We must first, however, refer to the technique of cross circulation because it would greatly influence flows used on CPB. On March 26th, 1954, Dr. C. Walton Lillehei of Minneapolis used cross circulation for the first time for open heart surgery. He did so because hypothermia did not allow adequate time for the correction of complex cardiac lesions and he was aware of the Azygous Principle which had been described by Andreason and Watson of Great Britian in 1950. They found that, in dogs, a cardiac oulput of 8-14 $\mathrm{ml} \cdot \mathrm{kg}^{-1} \cdot \mathrm{min}^{-1}$ could be sustained relying only on azygous vein blood flow to the heart, after ligation of the superior and inferior vena cava. This flow was adequate to support organ function for about $30 \mathrm{~min}$. When Dr. Lillehei had worked out the operation in the laboratory he took it to the operating room where he connected a volunteer to the patient who was to have cardiac surgery. The flow from the volunteer to the patient was controlled by a pump and limited to 20-25 $\mathrm{ml} \cdot \mathrm{kg}^{-1} \cdot \mathrm{min}^{-1}$ while the heart of the patient having the cardiac surgery was isolated. He operated on 45 patients with a mortality rate of $38 \%$. There were only six deaths in a 30 year follow-up of the survivors and there were no major complications in the volunteers. These results were obtained at a time when there were no blood gas analyses, electrolytes could only be obtained in four to six hours and there were no ventilators, pacemakers or defibrillators. ${ }^{16}$ 
On April 5th, 1951, Dennis and Varco, also of Minneapolis, began to use CPB clinically. They used a modification of the John Gibbon vertical screen oxygenator. The first patient was thought to have an ASD secundum but died because of misdiagnosis: the patient was found to have a PDA at postmortem. The second patient died when the blood level in the arterial reservoir was lost and the patient received a massive air embolus. In 1953, Dr. John Gibbon of Philadelphia who had been carrying out research on CPB since 1937, did his first clinical cases. The first patient with an ASD died, the second was a complete success which was the first with a totally mechanical pump and lung, and the third and fourth patients died. Dr. Gibbon was apparently very disturbed by this high mortality rate and some felt it affected him throughout his career. Between 1952 and 1955 Dr. Mustard in Toronto used CPB with monkey lungs as a biological oxygenator: three of 21 cases survived. ${ }^{13}$ On March 1st, 1955, Dr. Lillehei began to use $\mathrm{CPB}$ with dog lungs as a biological oxygenator and would have four survivors in 12 cases. In 1955, Dr. Lillehei in Minneapolis and Dr. John Kirklin, only 90 miles away at the Mayo Clinic in Rochester, began to use a total mechanical CPB machine. Dr. Lillehei, working in association with Dewall developed a disposable bubble oxygenator and used low flows in the range of $20-30 \mathrm{ml} \cdot \mathrm{kg}^{-1} \cdot \mathrm{min}^{-1}$ while Kirklin, who modified the Gibbon oxygenator, would use high flows. Both would achieve phenomenal successes.

Dr. Emerson Moffitt (Figure 10), when he finished his anaesthesia training at Dalhousie University in 1955, moved to the Mayo Clinic in Rochester where he worked with John Kirklin not only in the operating room but also in the laboratory. He is the Canadian anaesthetist who made the earliest important contributions to the development of CPB in the care of patients having anaesthesia for open heart surgery using CPB. He reported the relationship between blood flow and blood volume in extracorporeal circulation ${ }^{17}$ and cardiac support with the Gibbon oxygenator in 1957.18 In 1958, his M.S. thesis concerned the relationship of blood flow, blood volume, blood pressure, systemic vascular resistance, arterial and venous oxygen content, in patients supported by the Mayo-Gibbon oxygenator. The MayoGibbon CPB machine was a vertical sheet oxygenator contained in a lucite casing into which oxygen $97 \%$ and carbon dioxide $3 \%$ flowed at a rate of $11 \mathrm{~L} \cdot \mathrm{min}^{-1}$. There were automatic levelling devices on the arterial and venous reservoirs. The pump was primed with 4-4.5 L freshly drawn heparinized blood. A control station and operator were located in a gallery outside and above the operating room where all the variables that were measured were recorded during open heart

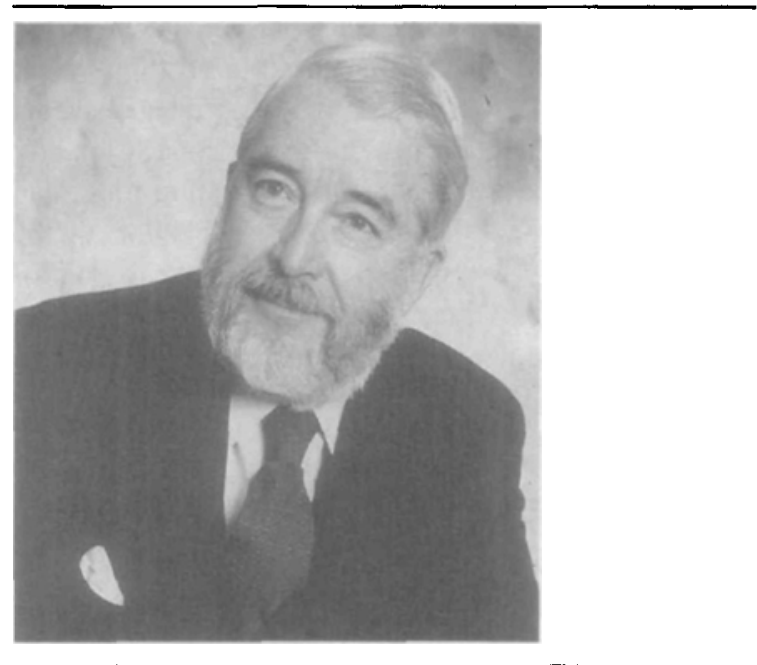

FIGURE 10 Dr. Emerson Moffitt: made the grearest contribution by a Canadian anaesthetist to the development of cardiopulmonary bypass and anaesthesia for patients having open heart surgery.

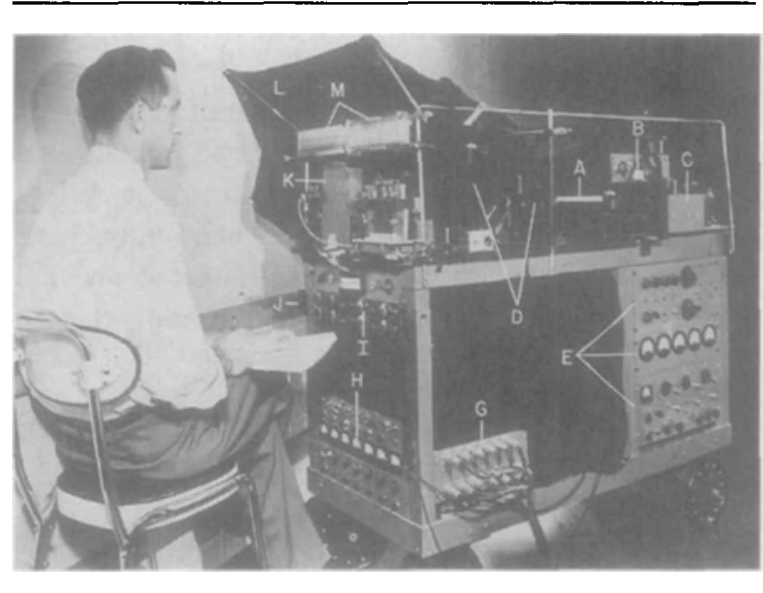

FIGURE 11 The control station and operator during open heart surgery.

surgery. (Figure 11) They wanted to be sure that pump flow was adequate for oxygenation and so measured cardiac output, pump flow, arterial and venous oxygen saturations. Clinically they maintained flows that would give acceptable physiological venous oxygen saturations.

Dr. Moffitt also wrote on the anaesthetic management of these patients. Premedication was with nembutal and morphine, induction with small amounts of thiopentone and maintenance with nitrous oxide, oxygen and ether with d-tubocurarine for relaxation. Patients were maintained lightly anaesthetized and their lungs were ventilated manually to maintain a low normal $\mathrm{PaCO}_{2}$. The 
ECG and EEG were monitored and there were arterial and venous lines for the measurement of pressure and oxygen saturation. The rectal temperature was measured and they tried to keep patients normothermic. Thus, Dr. Moffitt, working with Dr. Kirklin at the Mayo Clinic, was able to verify the adequacy of pump flow during CPB for oxygenation and detailed the important aspects of anaesthesia management. They used monitoring modalities far ahead of anyone at that time and equal to those used today. It was a remarkable contribution to the advance of cardiac surgery.

The first use of a total mechanical CPB machine in Canada was accomplished by Dr. John Callaghan (Figure 12) at the University Hospital, Edmonton, Alberta in 1956. Dr. E.A. Gain (Figure 13), Professor and Chairman of Anaesthesia, had worked with Callaghan in the laboratory and gave the anaesthetic for the first clinical procedure. They used a Dewall disposable bubble oxygenator and Callaghan was adamant that they follow the Lillehei technique to the letter, even down to the anaesthetic technique. Dr. Gain wrote to me that "for a time we stopped using our brains but like everyone else we soon started to do our own thing."

Dr. Gain described his anaesthetic experience using extracorporeal circulation for open heart surgery in 1957. ${ }^{19}$ Induction was with thiopentone or cyclopropane and succinylcholine used for intubation. Maintenance was with nitrous oxide, oxygen and ether analgesia, as described by Artusio in 1952. ${ }^{20}$ Basically, it was light anaesthesia with ether where muscle relaxants were not used and the patient could respond to verbal command. Dr. Gain told the author that "when low flows were used during $\mathrm{CPB}$, as recommended by Dr. Lillehei, that is $20-30 \mathrm{ml} \cdot \mathrm{kg}^{-1} \cdot \mathrm{min}^{-1}$, awakening on bypass was not a problem because of the cerebral hypoxia". When they began to use higher flows awakening became a problem and it was managed with $i v$ barbiturates, demerol and increments of succinylcholine $i v$. They monitored the ECG, EEG, arterial and venous pressures. Twenty five patients were reported with a $45 \%$ mortality rate. This was mainly due to postoperative metabolic acidosis when low flows were used and cardiac standstill subsequent to oedema of the cardiac conduction system. He did not find isoproterenol to be very effective for treating this problem and, of course, pacemakers were not available. $^{19}$

Dr. Gain wrote that he had "many memories, some happy, some fearsome. It was an exciting time. Growing up with the early phase of open heart surgery was a privilege given to few and to observe the change from an ordeal of pure terror to one of routine has been exciting." He recalled the time when they had to hurry back to the pump and protamine was given instead of

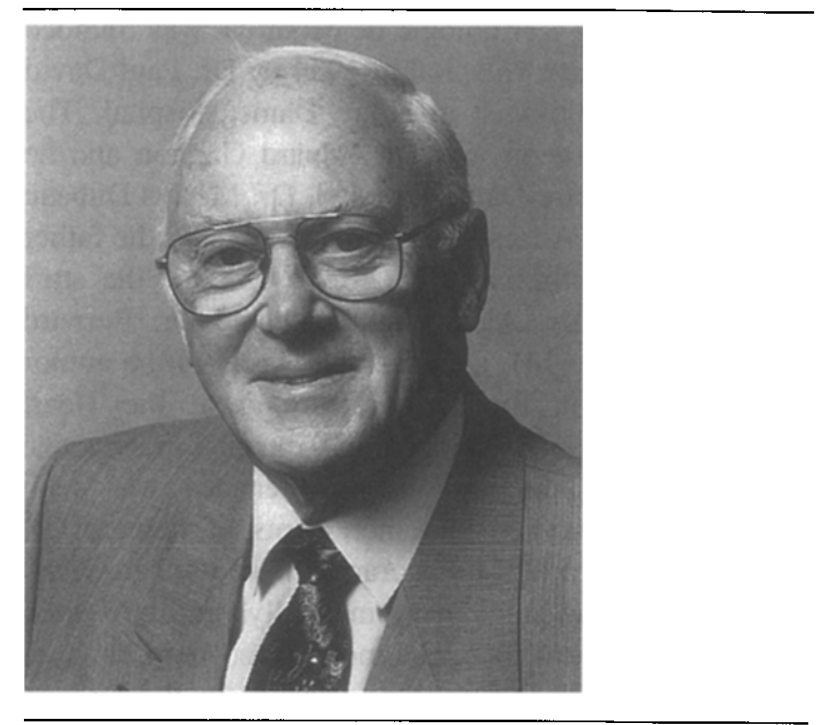

FIGURE 12 Dr. John Callaghan: performed the first open heart surgery in Canada at the University of Alberta in Edmonton in 1956 using a mechanical cardiopulmonary bypass machine.

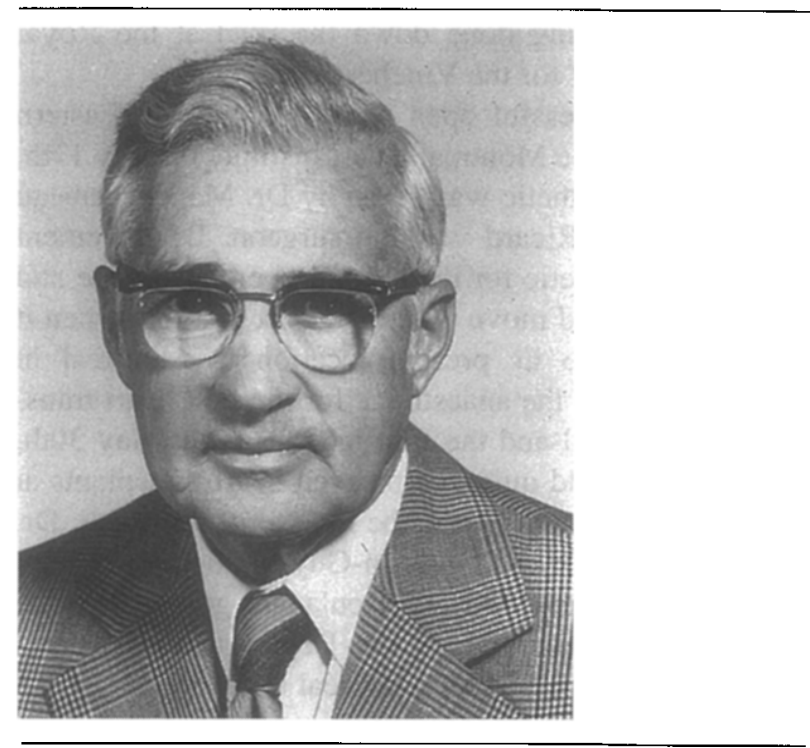

FIGURE 13 Dr. E.A. Gain: Professor and Chairman of the Department of Anaesthesia at the University of Alberta in Edmonton gave the anaesthetic for the first open heart procedure by Dr. John Callaghan.

heparin. Syringes were never preloaded after that. "How stupid we were weighing all the sponges before and after surgery and sending them back blue, vasoconstricted and hypovolaemic. We never seemed to remember Starling's Law." Dr. Gain gave his last anaesthetic for an open heart procedure in 1976, retired when he was 60 years of age and now lives in Sidney, B.C. 
The Institut de Cardiologie de Montréal was founded at the Maisonneuve Hospital in 1954 by Dr. Paul David who was a cardiologist at Nôtre Dame Hospital. The chief cardiac surgeon was Dr. Eduard Gagnon and he too was from Nôtre Dame Hospital. Dr. Marius Dubeau was the Chief of Anaesthesia and undoubtedly the father of cardiac anaesthesia in Montréal. Two of the staff members were Dr. Alex Wielhorski and Dr. Bernard Paiement (Figure 14). Dr. Paiement wrote to the author about anaesthesia for cardiac surgery at the Heart Institute in the 1950 s. Thiopentone, in small increments, was used for induction and maintenance was with nitrous oxide, oxygen and increments of demerol $i v$. Succinylcholine and d-tubocurarine were used for muscle relaxation, the lungs being manually ventilated via a cuffed endotracheal tube. His motto was "keep the eyes dry; the patient who cries wants anaesthesia, the surgeon who cries wants relaxation." Intravenous fluids were given through 16 or 18 gauge metal needles placed in a saphenous vein at the ankle and monitoring consisted of taking the blood pressure, feeling the pulse and observing the colour of the patient; in other words, much the same as was being done down the road at the Royal Victoria Hospital for the Vineberg operation.

The first successful open heart operation in Eastern Canada was at the Montréal Heart Institute on July 17th, 1957. The anaesthetic was given by Dr. Marius Dubeau and Dr. J.P.M. Ricard was the surgeon. Dr. Paiement gave the anaesthetic for the second open heart. He and Wielhorski would move with the Heart Institute when it was relocated to its present location in Montréal in 1964. They gave the anaesthetic for the first heart transplant in Montréal and the first in Canada on May 30th, 1968. They would quickly do seven heart transplants at the Institute but none would be long term survivors. Dr. Marcel Boulanger and Dr. Jean-Guy Maillé would soon join the anaesthetic staff and Boulanger go on to be the Professor and Chairman of the Department of Anaesthesia at the University of Montréal and Director of the Heart Institute.

Dr. William Dodds (Figure 15) gave the anaesthetic for the first open heart operation at the Vancouver General Hospital on October 29th, 1957. Dr. Dodds published on cardiac resuscitation in $1959^{21}$ based on his experience in managing cardiac arrest after open heart surgery. He detailed the important factors that would contribute to a successful outcome and, most importantly, recommended that a mobile cart be organized in every hospital that could be taken to patients who had a cardiac arrest outside the operating room. His recommendation is now a routine. He also decribed the anaesthetists' role in open heart surgery ${ }^{22}$ and acid base balance in open heart surgery. ${ }^{23}$
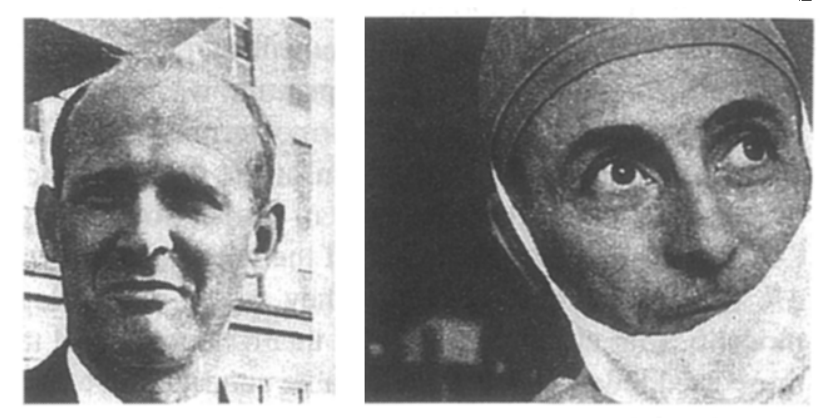

FIGURE 14 Dr. Bernard Paiement (lefi) and Dr. Alex Wielhorski: were on the attending staff in the Department of Anaesthesia at Maisonneuve Hospital when L'Institut de Cardiologie de Montreal was located there in the mid-1950's. They relocated when the institute moved to its present location in Montreal in 1964 and Dr. Paiement became the Chief of Anaesthesia.

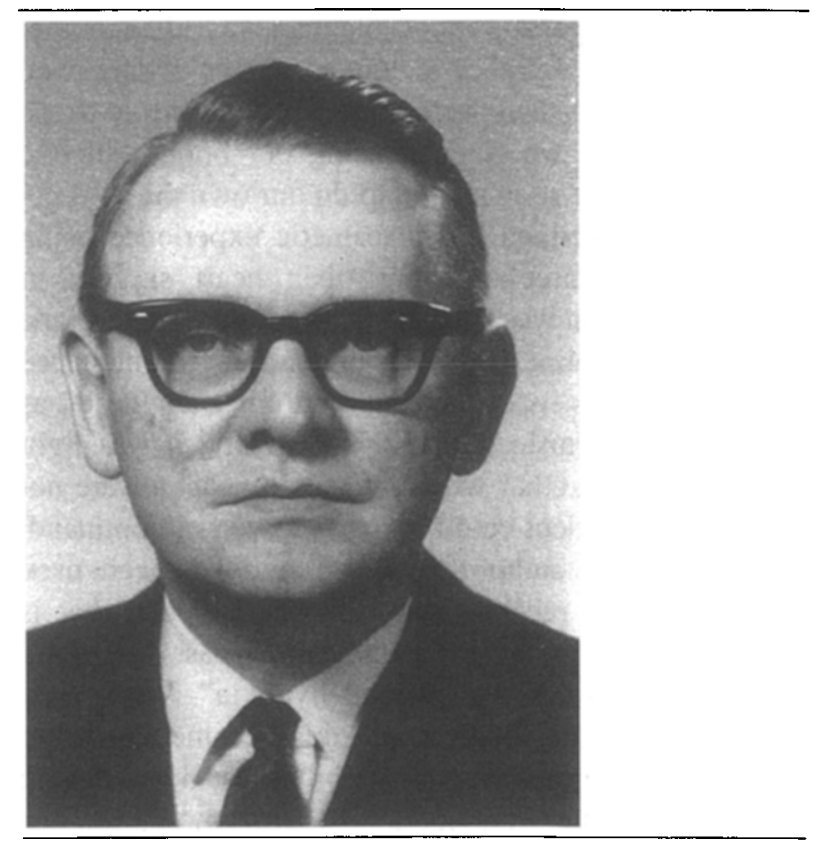

FIGURE 15 Dr. William Dodds: gave the anaesthetic for the first open heart at the Vancouver General Hospital.

At McGill University Dr. A.R.C. Dobell (Figure 16), after completing his cardiac surgery training with John Gibbon in Philadelphia, returned to Montréal and was committed to organize an open heart surgery programme. In 1956 he was appointed to the staff of the Montréal Children's Hospital and the Royal Victoria Hospital. Both institutions were interested in starting an open heart surgery programme. On Saturday mornings they would practise open heart surgery on dogs in the operating room of the old Children's Hospital which was situated opposite the Montréal General Hospital on 


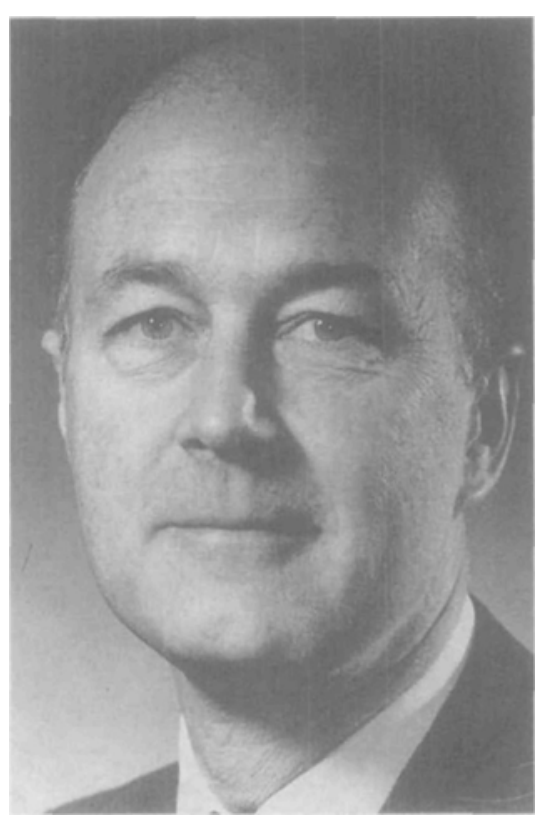

FIGURE 16 Dr. A.R.C. Dobell: after completing his training with Dr. John Gibbon, returned to McGill University and instituted the open heart surgery programme.

Cedar Avenue. It was at this location that Dr. Arthur Sheridan and his patient survived an ether explosion and fire.

The first open heart at the Montréal Children's Hospital was on February 14, 1957. The patient had a VSD but did not survive, nor did the next three cases. The first successful open heart procedure was a VSD repair on November 13, 1957. The patient was an eight year old girl, weighing $17.2 \mathrm{~kg}$. Premedication was with nembutal, morphine and scopolamine. The patient was apprehensive on arrival in the induction room. Anaesthesia was induced with rectal thiopentone and maintenance was with nitrous oxide, oxygen and $\mathrm{d}$ tubocurarine. Dr. H.T. Davenport, Chief of Anaesthesia, gave the anaesthetic. Others who gave anaesthetics for these procedures included: Dr. Alex MacDonald, Dr. José Rosales and Dr. Paul Kwan. It was Dr. Rosales (Figure 17) who made the greatest contribution to the advancement of cardiac anaesthesia at the Children's Hospital in Montréal. He had'superb knowledge, technical skills and judgement and the author was privileged to be supervised by him when a senior resident in 1958 . When I moved to the Royal Victoria Hospital as a clinical fellow in July of 1958, two open hearts had been done at that hospital. The anaesthetists who had given the anaesthetics were Dr. Alan Noble the Chief of Anaesthesia, Dr. Arthur Sheridan, Dr. Anne Richardson

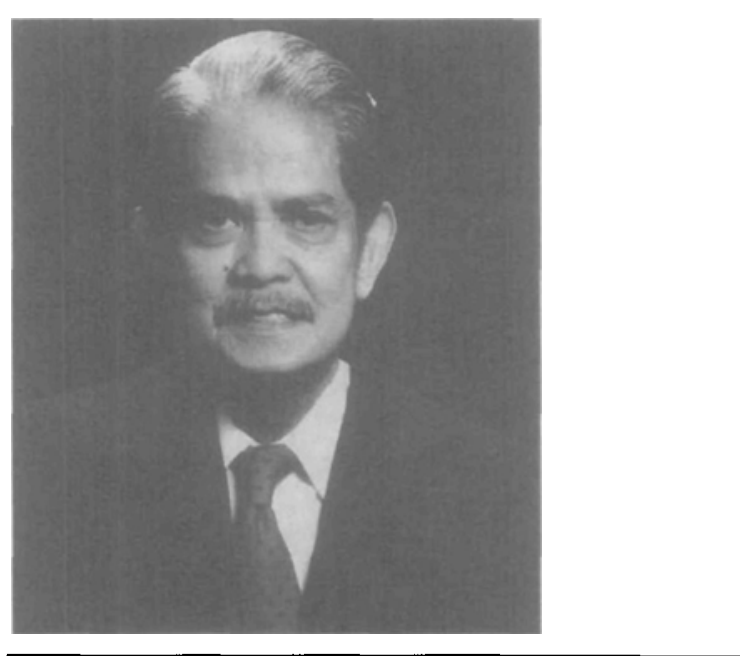

FIGURE 17 Dr. Jose Rosales: advanced cardiac anaesthesia at the Children's Hospital in Montreal and supervised the author as a senior resident in 1958.

and Dr. Gordon Robson. All were on vacation when Dr. Vineberg announced he had an 11 year old male patient with subaortic stenosis who required surgery. When informed that the open heart anaesthesia team was on vacation he suggested an anaesthetist from the Children's Hospital be obtained. Dr. Gladys Ellison, who was the Acting Chief in Dr. Noble's absence, was aware that I had done anaesthesia for open heart cases at the Children's Hospital and asked me if I would care to do the case. I jumped at the chance and she assisted me. I became a member of the cardiac anaesthesia team, was given a permanent staff position and soon Dr. Noble would put me in charge of Cardiac Anaesthesia. This field was wide open and the potential for advancing clinical care, teaching and research was enormous.

Dr. Sallie Teasdale-Scott (Figure 18), as an intern, scrubbed at the first open heart operation at the Toronto General Hospital in 1957. When she finished her anaesthesia training she joined the Department of Anaesthesia at the Toronto General Hospital and said she jumped at the chance to become a member of the cardiac anaesthesia team headed by Dr. Barrie Fairley. She wrote to me that "patients who came to surgery in the late 1950's and 1960's had reached a terminal stage. The cardiologist, after years of digoxin and diuretics had finally given up and surrendered the patient to the surgeon after the administration of last rights. Many an hypoxic, cachectic patient was in bubbling congestive heart failure with rapid atrial fibrillation outside the operating room door; small wonder the mortality was so high."

I too have similar memories, recalling losing many patients who were in terminal heart failure with valvular 


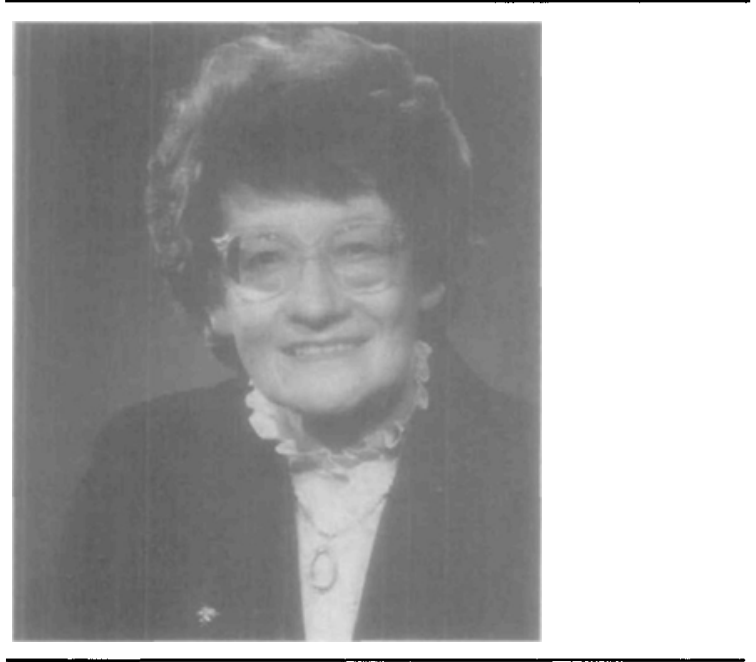

FIGURE 18 Dr. Sallie Teadsale-Scott: as an intern, scnubbed on the first open heart surgical procedure at the Toronto General Hospital in 1957 She became a member of the cardiac anaesthesia team headed by Dr. Barrie Fairley and would go on to be Director of Cardiac Anaesthesia and head of the Post Cardiac Surgery Intensive Care Unit.

disease when they were referred for surgery. We had to convince the cardiologists to refer the patients earlier in their disease process to avoid an unacceptable mortality rate. When the cardiologists agreed, the mortality rates began to decrease. Dr. Teasdale would go on to head the Cardiac ICU at the Toronto General Hospital and, in collaboration with Dr. Glynn, published the first paper on the use of ancrod as an alternative to heparin in open heart surgery. ${ }^{24}$

There is a distinguished history of anaesthesia at Laval University in Quebec City. Dr. Fernando Hudon, the Chief of Anaesthesia at the Hôtel Dieu Hospital, anaesthetized a patient in 1949 with so-called "refrigeration anaesthesia" which really was the lytic cocktail for the implantation of a Hufnagel valve. The anaesthetic record has been lost or destroyed but that it occurred is documented in the archives of the hospital where it is noted that Dr. Hudon presented a paper in Paris in 1950 on refrigeration anaesthesia for the implantation of a Hufnagel valve. Dr. J.P. Déchêne (Figure 19) after completing his anaesthesia training at Laval University, spent a year with Dr. McQuistin in Chicago in 1949. On returning to Laval University in 1950, JP spent a short time at the Hôtel Dieu Hospital before moving to the Laval Hospital where he concentrated on anaesthesia for pulmonary surgery and experimental cardiac surgery. Other members of the team included Dr. Andre McClish, an anaesthetist who designed their CPO machine and the surgeon Dr. Gravel. Dr. Gravel had

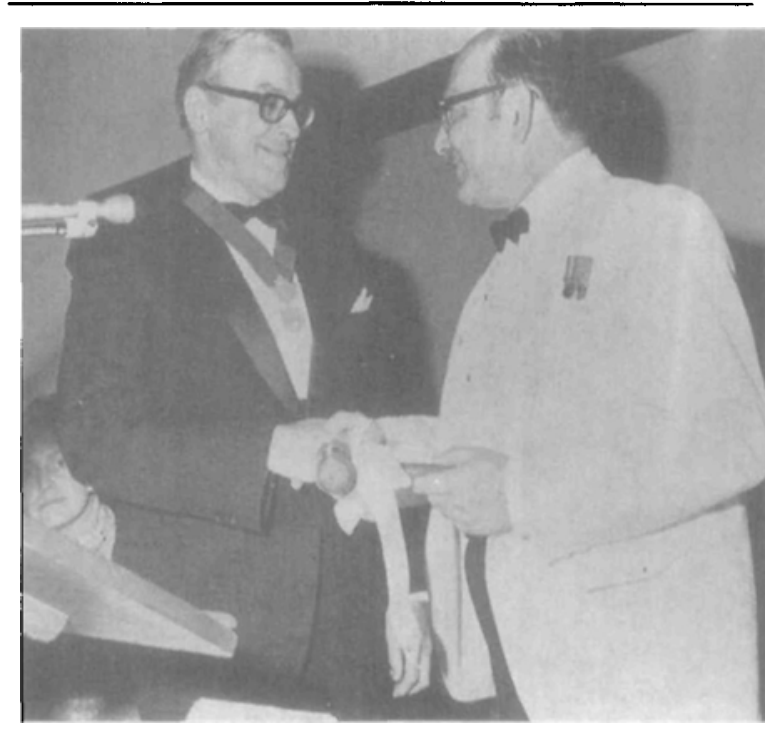

FIGURE 19 Dr. J.P. Déchêne: is shown (left) being installed as President of the Canadian Anaesthetists' Society in 1972 by Past President Dr. Gordon Wyant. He pioneered anaesthesia for pulmonary and cardiac surgery at Laval University.

spent some time at the Karolinska Institute in Sweden and brought back the Carlen tube. One day when inserting one, having done so in about 150 cases by 1952, Dr. Déchêne was informed that the visitor sitting in the corner of the operating room was Dr. Carlen. I asked him what was his response: he merely chuckled. In their experimental laboratory they had a Crawford ventilator powered by air which was not available to them. Dr. Déchêne went out and bought an Electrolux vacuum cleaner which he used to power the ventilator. They did their first clinical open heart operation on Holy Thursday, 1959, with Dr. A.R.C. Dobell and Dr. José Rosales being present by invitation. In the 1970s, Dr. Déchêne taught cardiac resuscitation to the public in Québec City and in Montréal. His programme was a forerunner of the current ACLS Programme.

In Ottawa, although a few Vineberg procedures, mitral commissurotomies and open heart procedures had been done in the mid-sixties, a cardiac programme did not get underway until Dr. W.J. Keon, the surgeon, (Figure 20), returned in 1967. He is a University of Ottawa Medical graduate who did his surgical training at McGill University and cardiac surgery training at the University of Toronto after which he obtained his $\mathrm{PhD}$ in physiology at Harvard. He was driven by a vision to create a Heart Institute in Ottawa which he did in 1976.

Dr. John Atkinson (Figure 21), on completing his anaesthesia training at McGill, joined the anaesthesia 


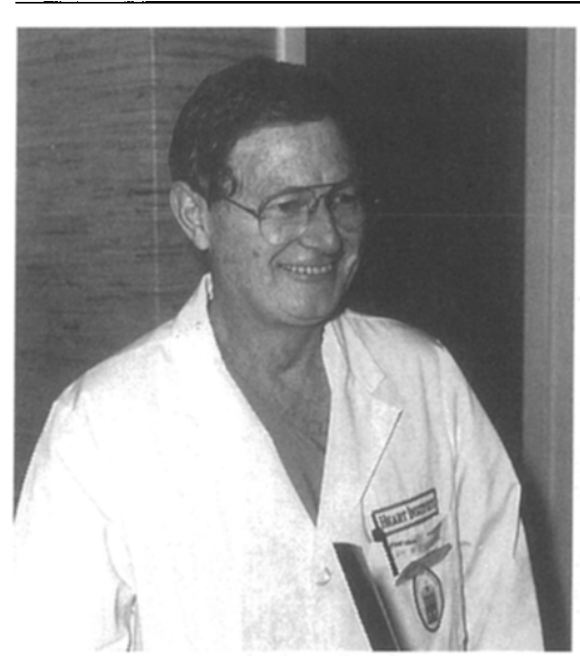

FIGURE 20 Dr. W.J. Keon: founded the University of Ottawa Heart Institute in 1976.

staff at the Ottawa Civic Hospital in 1974 and headed the cardiac anaesthesia team that would work with Dr. Keon. Drs. John Cowan, Barrie Wilson and Ruaraidh McIntyre were other members of the anaesthesia team. Dr. Keon implanted the first total artificial heart in Canada in 1986 . The patient was a 42 year old woman with coronary artery disease who underwent emergency CABG surgery in cardiogenic shock and could not be weaned from CPB. She was supported with a Jarvick 7-70 artificial heart until she underwent a successful heart transplantion. She is alive and well today. Dr. McIntyre gave the anaesthetic. By June 1995, the Jarvick 7-70 artificial heart had been used in 20 patients as a bridge to transplantion at the Heart Institute with a successful outcome in 12 .

The first neonatal transplant in Canada was done at the Heart Institute on August 2, 1989. The patient had hypoplasia of the left ventricular outflow track, was 11 days old and weighed $3.6 \mathrm{~kg}$. The donor was $2 \frac{1}{2}$ yr old and weighed $8 \mathrm{~kg}$. In spite of the discrepancy in size the operation was successful and the patient is thriving. Dr. Charles Cattran gave the anaesthetic.

Mr. Perrin Johnson underwent heart transplantion at St. Michael's Hospital in Toronto on November 17th, 1968. He was the first long term survivor in Canada, lived $91 / 2$ years and would be the longest heart transplant survivor in the world in the pre-cyclosporin era. The anaesthetic team was headed by Dr. Donald Finlayson (Figure 22). He was a pioneer of cardiac anaesthesia and intensive care at St. Michael's Hospital in Toronto before moving to Emory University in Atlanta, Georgia. $\mathrm{He}$ also headed the team which negotiated the Ontario

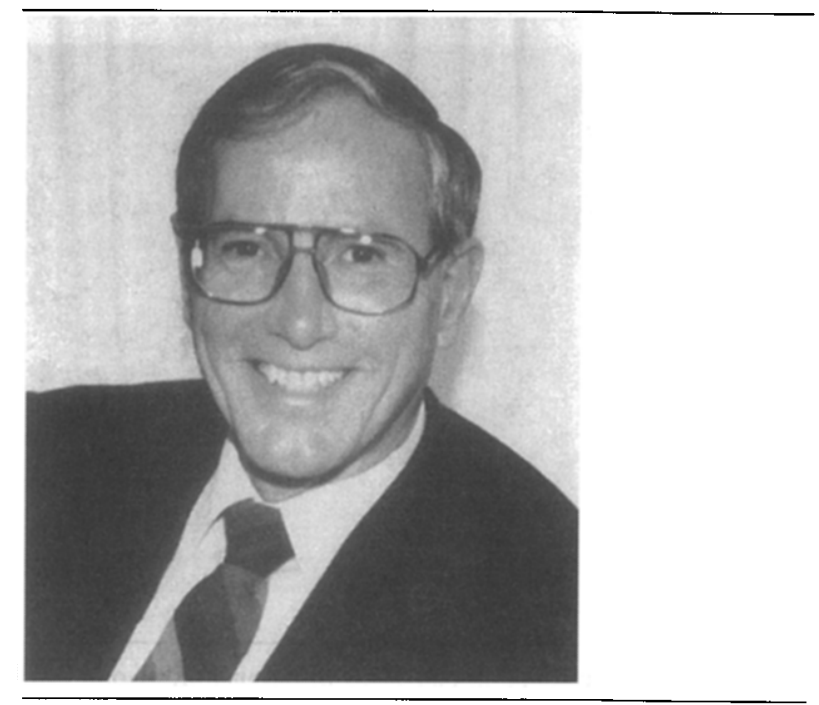

FIGURE 21 Dr. John Atkinson: head of the cardiac anaesthesia team who worked with Dr. W.J. Keon.

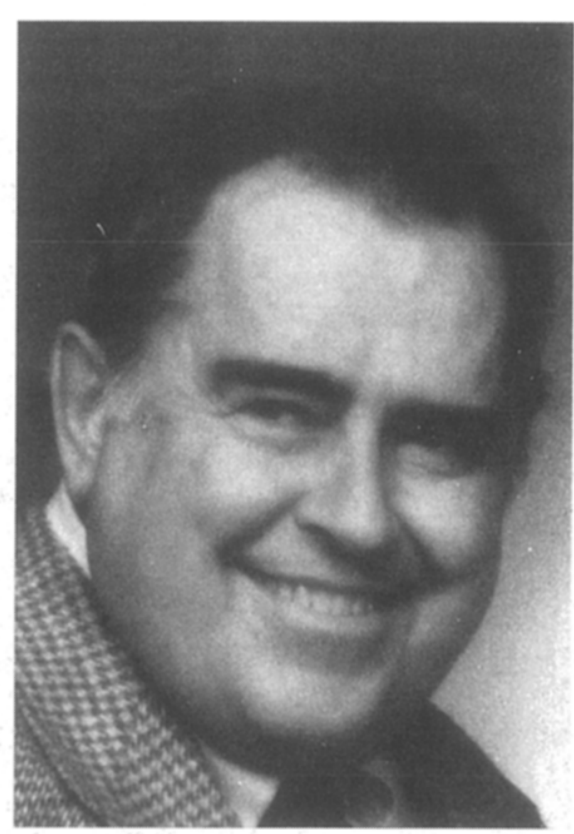

FIGURE 22 Dr. Donald Finlayson: a pioneer of cardiac anaesthesia and intensive care at St. Michael's Hospital in Toronto in the 1960's gave the anaesthetic for the longest surviving heart transplant in the pre-cyclosporin era in the world.

anaesthesia fee schedule when medicare was introduced.

Mr. John Parkinson (Figure 23), aged 53 years, underwent heart transplantion at the Royal Victoria Hospital in Montréal on November 3rd, 1969. I remem- 


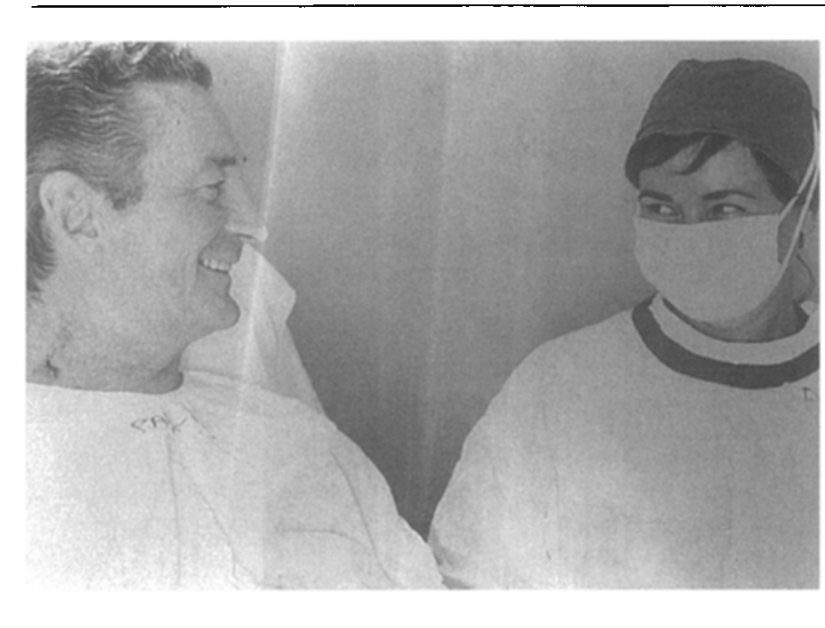

FIGURE 23 Mr. John Parkinson and his wife Anne: shown on approximately the 10th postoperative day following the first heart transplant done at the Royal Victoria Hospital in 1969. He survived for four years

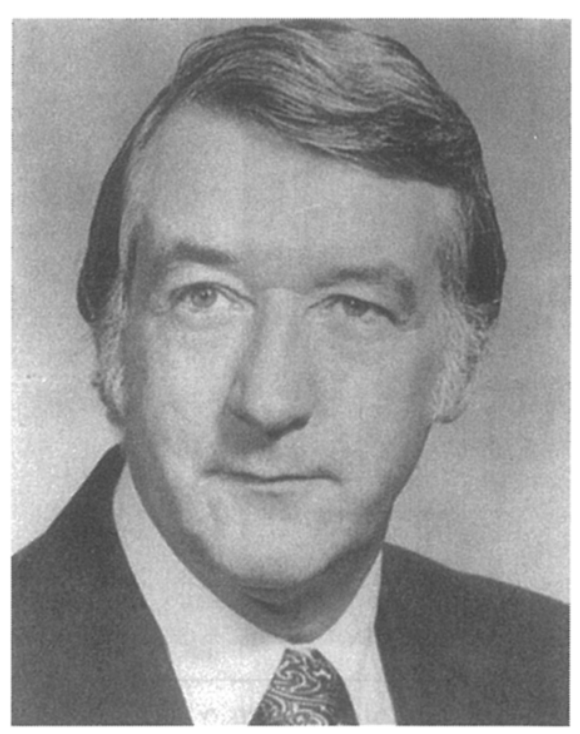

FIGURE 24 Dr. Germain Houle: of the Department of Anaesthesia at the Royal Victoria Hospital was a member of the anaesthesia team who looked after Mr. Parkinson.

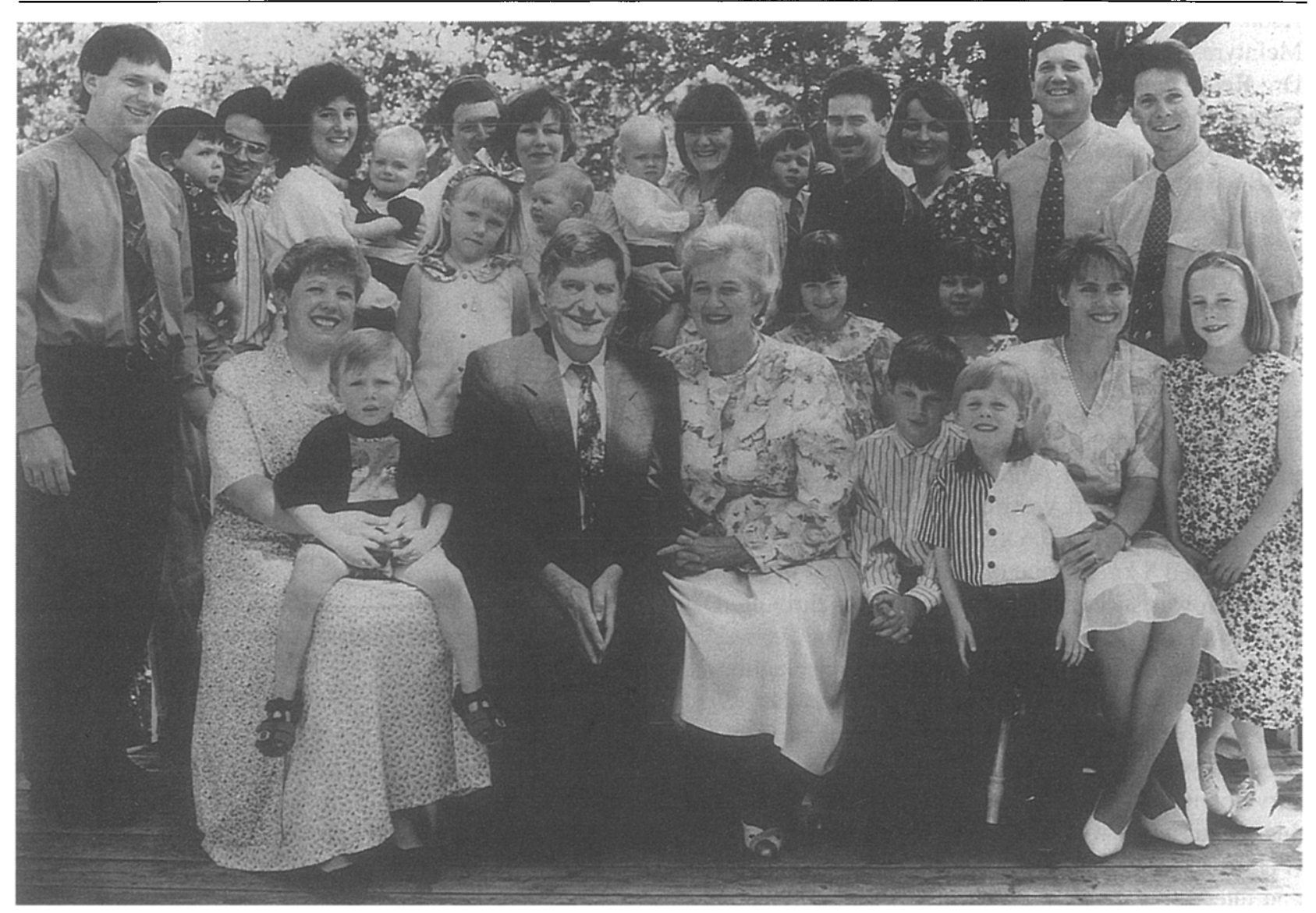

FIGURE 25 Dr. Earl and Mary Wynands, their children, spouses and grandchildren. 
ber the date very well because it was my mother's birthday and on that Sunday afternoon I had to call home and say I would not be at her birthday party. Mr. Parkinson lived for four years, died of a stroke and would be the second longest survivor of a heart transplant in the precyclosporin era. The author was the member of the transplant team who established close rapport with $\mathrm{Mr}$. Parkinson and would frequently see or be contacted by him when Mr. Parkinson ran into problems, real or perceived. The author vividly remembers many interesting times with Mr. Parkinson. Once, after having had his driving license renewed, he decided to buy a sports car. He went to a dealer and, in negotiating the price, he opened his shirt, showed his scar and said he felt he should receive special consideration as he was probably the first heart transplant paticnt to go out and purchase a new car. He received a good deal. Dr. Germaine Houle (Figure 24), a member of the anaesthesia staff at the Royal Victoria Hospital, was the other anaesthetist who worked with me and Dr. Basil Kuriyan, a resident in anaesthesia, managing Mr. Parkinson and the donor.

Cardiac anaesthesia in Canada is alive and well with a great future due to the many men and women dedicated to improving the clinical care of patients with heart disease through research and teaching. I believe we are doing an excellent job in cardiac anaesthesia, indeed much better than we give ourselves credit. Anaesthesia has been consistently responsible for reducing morbidity and mortality in cardiac surgery.

I would not have been asked to give the Royal College Lecture were it not for the enormous support I have received from my colleagues in Anaesthesia and Surgery over the past 40 years, until 1988 at McGill University and since then at the University of Ottawa Heart Institute. I am greatly indebted to all of my peers. Most of all, however, I am indebted to my family (Figure 25): My wife Mary has given me incredible support and both of us have been encouraged by our daughters Mary Jane and Nancy, our sons John, Grant, Bob and Paul, their spouses and our 12 grandchildren. I also want to thank the many anaesthetists and surgeons who wrote to me or who called me with information I requested. This article would have been impossible without their assistance and that of Mary O'Shaughnessy-Partington who assisted in the preparation of the manuscript.

\section{References}

I Harold N. Segall. Pioneers of Cardiology in Canada 1820-1970. Willowdale, Ontario: Hounslow Press, 1988.

2 Ellis $R H$. The first trans-auricular mitral valvotomy. Anacsthesia 1975; 30: 374-90.

3 Harmel MH, Lamont A. Anesthesia in the surgical treat- ment of congenital pulmonic stenosis. Anesthesiology 1946; 7: 477-98.

4 Keown KK. Anesthesia for Surgery of the Heart, Ist ed. Springfield, Illinois: Charles C. Thomas, 1956.

5 Evelyn SJ, MacKay I. Anesthetic for Cardiac Surgery. Current Researches in Anesthesia and Analgesia 1954; May-June: 186-94.

6 Fortin $G$, Létienne R. Prophylaxis and treatment of cardiac arrest. Can Anaesth Soc J 1954; 1: 24-31.

7 Little DM Jr, Sutton GC. Succinylcholine-nitrous oxide anaesthesia for mitral commissurotomy. Can Anacsth Soc J 1955; 2: 156-71.

8 Bigelow WG, Lindsay WK, Harrison RC, Gordon RA, Greenwood WF. Oxygen transport and utilization in dogs at low body temperatures. Am J Physiol 1950; 160: 125-37.

9 Smith $C$. Anaesthesia for the surgical correction of congenital heart discase. Can Anaesth Soc J 1955; 2: 347-53.

10 Fairley $H B$. Hypothermia for adult cardiovascular surgery: a technique of anacsthesia. Can Anaesth Soc J 1957; 4: 96-103.

11 Conn $A W$, Allan D, Junkin Cl. Anaesthesia with hypothermia for closure of atrial septal defects in children. Can Anacsth Soc J 1959; 6: 327-36.

12 Conn AW, Millar RA. Post occlusion hypertension and plasma catecholamine levels. Can Anaesth Soc J 1960; 7: 443-6.

13 Mustard WT, Thomson JA. Clinical experience with the artificial heart lung preparation. Can Med Assoc J 1957; 76: 265-9.

14 Wynands JE, Sheridan $C A$, Kelkar $K$. Coronary artery discase and anaesthesia (experience in 120 patients for revascularization of the heart). Can Anaesth Soc J 1967; 14: 382-98.

15 Wynands JE, Sheridan CA, Batra MS, Palmer WH, Shanks J. Coronary artery disease. Anesthesiology 1970; 33: 260-81.

16 Lillehei $C W$. Historical development of cardiopulmonary bypass, I $n$ : Gravlee GP, Davis RF, Utley JR (Eds.). Cardiopulmonary Bypass Principles and Practice, Ist ed. Baltimore, Maryland: Wiliams \& Wilkins, 1993: 1-26.

17 Donald ED, Moffitt EA. Studies in extracorporeal circulation. IIl. The relation of blood flow and blood volume during extracorporeal circulation in man. Surg Forum 1957; 7: 264-7.

18 Patrick RT, Theye RA, Moffitt EA. Studies in cxtracorporeal circulation. $V$. Anesthesia and supportive care during intracardiac surgery with the Gibbon-lype pump-oxygenator. Anesthesiology 1957; 18: 673-85.

19 Gain EA. Anacsthetic experiences using extracorporeal circulation for open heart surgery. Can Anaesth Soc $J$ 1957; 4: 419-27. 
20 Artusio JF Jr. Anesthesia management of the rheumatic cardiac for mitral valvulotomy. The Bulletin 1953; 684-6.

21 Dodds WA, Ashmore PG. Cardiac Resuscitation. Can Anaesth Soc J 1959; 6: 75-82.

22 Dodds WA, Graves HB, Nixon JE, Davies LE, Sleath GE. The anaesthetist's role in open heart surgery. Can Anacsth Soc J 1961; 8: 239-46.

23 Dodds WA, Forseng EG. Study of acid-base balance in open-hcart surgical patients. Can Anaesth Soc J 1962; 9: 488-96.

24 Zulys VJ, Teasdale SJ, Michel ER et al. Ancrod (Arvin(B) as an alternative to heparin anticoagulation for cardiopulmonary bypass. Anesthesiology 1989; 71: 870-7. 